\title{
ASPECTOS ERGONÔMICOS E DISTANCIAMENTO SOCIAL ENFRENTADOS POR DOCENTES DE GRADUAÇÕES A DISTÂNCIA DURANTE A PANDEMIA
}

\author{
Fátima Aurilane de Aguiar Lima Araripe ${ }^{1}$, Renata Vieira do Nascimento ${ }^{2}$ \\ Lydia Dayanne Maia Pantoja ${ }^{3}$, Germana Costa Paixão ${ }^{4}$
}

\section{RESUMO}

Diante as dificuldades do trabalho home office gerado pela pandemia da COVID-19, principalmente considerando os docentes universitários, o presente trabalho objetivou investigar os aspectos ergonômicos e os impactos do distanciamento social vivenciados por tutores e professores formadores de cursos de graduação a distância de uma universidade cearense, em um contexto pandêmico. Trata-se de uma pesquisa descritiva de cunho qualitativo e quantitativo, com aplicação de questionário on-line constituído por 37 questões (objetivas/subjetivas). Participaram 146 indivíduos, dos quais 56,2\% eram mulheres, com média etária de 41 anos. 54,1\% relataram ritmo de trabalho acelerado, 37,7\% apresentam desconforto físico e 34,9\% desconforto emocional. 83,6\% estão praticando o distanciamento social, $63,7 \%$ apresentaram alterações de sono, $65,8 \%$ têm consumido mais alimentos, $94,5 \%$ têm assumido mais obrigações domésticas/familiares, mesmo assim 48,6\% mantiveram a produtividade. Por fim, espera-se assessorar os gestores na dinâmica das atividades de graduações a distância e permitir uma reflexão da prática educacional em tempos adversos.

Palavras-chave: Ergonomia. Tutor. Professor formador. COVID-19.

\section{Como citar este documento - ABNT}

ARARIPE, Fátima Aurilane de Aguiar Lima; NASCIMENTO, Renata Vieira do; PANTOJA, Lydia Dayanne Maia; PAIXÃO, Germana Costa. Aspectos ergonômicos e distanciamento social enfrentados por docentes de graduações a distância durante a pandemia. Revista Docência do Ensino Superior, Belo Horizonte, v. 10, e024713, p. 1-19, 2020. DOI: https://doi.org/10.35699/22375864.2020.24713.

\footnotetext{
${ }^{1}$ Universidade Estadual do Ceará/Universidade Aberta do Brasil (UECE/UAB), Fortaleza, CE, Brasil. ORCID ID: https://orcid.org/0000-0002-4245-4102. E-mail: fatima.aurilane@uece.br 2 Universidade Estadual do Ceará/Universidade Aberta do Brasil (UECE/UAB), Fortaleza, CE, Brasil. ORCID ID: https://orcid.org/0000-0001-8309-5815. E-mail: renata.nascimento@uece.br ${ }^{3}$ Universidade Estadual do Ceará/Universidade Aberta do Brasil (UECE/UAB), Fortaleza, CE, Brasil. ORCID ID: https://orcid.org/0000-0002-4446-7230. E-mail: lydia.pantoja@uece.br ${ }^{4}$ Universidade Estadual do Ceará/Universidade Aberta do Brasil (UECE/UAB), Fortaleza, CE, Brasil. ORCID ID: https://orcid.org/0000-0003-3232-8863. E-mail: germana.paixao@uece.br
} 


\section{ASPECTOS ERGONÓMICOS Y AISLAMIENTO SOCIAL ENFRENTADOS POR PROFESORES UNIVERSITARIOS A DISTANCIA DURANTE LA PANDEMIA}

\section{RESUMEN}

Ante las dificultades del trabajo desde casa generadas por la COVID-19, especialmente considerando a los profesores universitarios, este estudio objetivo investigar los aspectos ergonómicos y los impactos del aislamiento social que experimentan los tutores y docentes que forman carreras de educación a distancia en una universidad de Ceará, en un contexto de pandemia. Se trata de una investigación descriptiva cualitativa y cuantitativa, con la aplicación de un cuestionario online que consta de 37 preguntas (objetivas/subjetivas). Participaron 146 personas, de las cuales $56,2 \%$ fueron mujeres, con una edad promedio de 41 años. 54,1\% refirió un ritmo de trabajo acelerado, $37,7 \%$ tiene malestar físico y $34,9 \%$ malestar emocional. $83,6 \%$ está practicando el aislamiento social, $63,7 \%$ ha tenido trastornos del sueño, $65,8 \%$ ha consumido más alimentos, $94,5 \%$ ha asumido más obligaciones domésticas/familiares, pero $48,6 \%$ mantuvo la productividad. Finalmente, se espera asesorar a los gestores en la dinámica de las actividades y permita una reflexión sobre la práctica educativa en tiempos adversos.

Palabras clave: Ergonomía. Tutor. Profesor formador. COVID-19.

\section{ERGONOMIC ASPECTS AND SOCIAL ISOLATION FACED BY DISTANCE GRADUATE TEACHERS DURING THE PANDEMIC}

\section{ABSTRACT}

Given the difficulties of the home office work generated by the pandemic of COVID-19, especially considering university teachers, the present study aimed to investigate the ergonomic aspects and the impacts of social isolation experienced by tutors and teachers who form students from distance undergraduate courses, at a Ceará university. This is a descriptive qualitative and quantitative research, with the application of an online questionnaire consisting of 37 questions (objective/subjective). 146 individuals participated, of whom $56.2 \%$ were women, with a mean age of 41 years. $54.1 \%$ reported an accelerated work rate, $37.7 \%$ had physical discomfort and $34.9 \%$ had emotional discomfort. $83.6 \%$ are practicing social isolation, $63.7 \%$ had sleep changes, $65.8 \%$ have consumed more food, $94.5 \%$ have assumed more domestic/family obligations, yet $48.6 \%$ have maintained productivity. Finally, it is expected to advise managers on the dynamics of distance learning activities and allow reflection on educational practice in adverse times.

Keywords: Ergonomics. Tutor. Teacher trainer. COVID-19. 


\section{INTRODUÇÃO}

A pandemia da COVID-19, causada pelo vírus SARS-CoV-2, que surgiu no final de 2019, vem acarretando transformações na sociedade, com consequências sobre o comportamento dos indivíduos. O rápido contágio e o aumento da quantidade de óbitos geraram insegurança na população, intensificando os sintomas de ansiedade, estresse e depressão (ODRIOZOLAGONZÁLEZ et al., 2020).

Shigemura et al. (2020) e Ornell et al. (2020) apontam, como efeitos da pandemia, as rupturas sociais, os impactos econômicos e sobre a saúde física e mental, destacando o aumento da ansiedade, do medo e do sentimento de incerteza. Neste sentido, o distanciamento social, necessário para evitar a transmissão do agente etiológico em questão, acarretou mudanças na rotina de trabalho, nos cuidados com a casa, no descanso e no lazer dos indivíduos.

Com o aumento do número de casos da doença COVID-19 no mundo, rapidamente o Brasil foi atingido, e, três meses após a identificação dos primeiros casos da doença na China, vários estados brasileiros iniciaram o distanciamento social, o que levou o mercado a uma nova realidade. Além dos impactos no setor financeiro e em outros, a educação também precisou adaptar-se ao novo cenário, uma vez que escolas e universidades tiveram suas atividades presenciais interrompidas, fazendo-se necessário um planejamento para que ensino, pesquisa e extensão continuassem acontecendo, sem prejuízos aos estudantes.

Sahu (2020) aponta como adversidades do trabalho docente on-line e home office: dificuldades no uso de tecnologias; poucos equipamentos de informática para grande demanda de uso em casa; falta de suporte das universidades para facilitar e manter o ensino on-line; além das limitações para ministrar aulas práticas, de laboratório, de campo e estágios. Ainda é preciso lidar com outros obstáculos, como o de alunos que não possuem computadores ou outros equipamentos de acesso e/ou internet para acompanhar as atividades remotas.

Neste sentido, o corpo docente de Instituições de Ensino Superior (IES) de cursos de graduação presencial e a distância tiveram que migrar sua atuação para as plataformas de ensino on-line. Em graduações a distância, o impacto foi menor, apesar de existirem em alguns cursos encontros presenciais nos polos de apoio, aulas de campo, estágios supervisionados em escolas, dentre outras atividades, que também tiveram que se adequar a essa nova configuração social. Logo, o contexto pandêmico trouxe novos desafios ao processo de ensino e aprendizagem, além de intensificar os já existentes. 
Em cursos que funcionam na modalidade a distância, parte das dificuldades supracitadas são minimizadas, tendo em vista que os alunos já possuíam uma rotina de realização de atividades on-line e que os profissionais têm treinamento específico para o trabalho remoto.

No caso dos cursos de graduação a distância de uma universidade de referência no estado do Ceará, campo de estudo desta pesquisa, as atividades que ocorrem de forma presencial são os encontros com os professores formadores, avaliações formativas, estágios supervisionados, desenvolvimento de projetos de pesquisa, de extensão, atividades de monitorias e grupos de estudos. Assim, devido ao momento pandêmico, essas práticas passaram por adaptações, para que não houvesse prejuízo no processo de ensino e aprendizagem, ou foram temporariamente suspensas, como foi o caso dos estágios supervisionados nas escolas, atividade imprescindível em cursos de licenciatura.

Neste sentido, o planejamento emergencial aumentou a demanda das reuniões remotas, devido à necessidade de adequação das ações que já haviam sido planejadas para o semestre vigente, considerando também as indefinições das atividades dos semestres subsequentes. Destarte, as fragilidades físicas e emocionais frente às incertezas geradas pela pandemia levaram muitos profissionais docentes a sentirem-se sobrecarregados, fato que impulsionou a realização da presente pesquisa.

Dentro desse contexto, o estudo dos aspectos ergonômicos, na atuação desses profissionais, vislumbra importância ímpar, visto que a "análise ergonômica do trabalho é essencial para que as atividades incumbidas aos executores sejam realizadas sem prejuízos físicos, psicológicos e materiais, obedecendo aos critérios mínimos das condições de trabalho" (PAULA et al., 2018, p. 2). Para tanto, a Norma Regulamentadora - NR17, do Ministério do Trabalho e Emprego, considera aspectos que devem ser observados para estabelecer condições favoráveis, dentre elas os equipamentos, as condições ambientais do posto de trabalho e a organização do trabalho (BRASIL, 2007).

Segundo Richter (2020), para alguns profissionais, o tempo disponível para o trabalho pareceu ser maior, enquanto para outros imperaram as dificuldades de trabalhar e cuidar dos filhos, de compartilhar equipamentos e espaço de trabalho com outras pessoas da casa, além de lidar com a rotina doméstica diária. Ademais, o elevado número de videoconferências e interrupção das interações físicas tornaram o trabalho mais estressante e cansativo.

Frente às dificuldades do trabalho home office gerado pela pandemia, o presente artigo objetiva investigar os aspectos ergonômicos e impactos do distanciamento social enfrentados por tutores e professores formadores de cursos de graduação a distância de uma universidade no estado do Ceará. 


\section{PERCURSO METODOLÓGICO}

Trata-se de uma pesquisa descritiva de cunho qualitativo e quantitativo (GIL, 2008) que visou confrontar as hipóteses e correlacionar as variáveis para obter as respostas e analisá-las. Para tanto, fez uso de cálculos matemáticos e, no caráter subjetivo, usando narrativas, a presente pesquisa teve, como campo de investigação, 22 cursos de graduação e pós-graduação lato sensu a distância de uma instituição pública de ensino superior.

A universidade em questão é uma das seis instituições públicas do estado do Ceará que participam do sistema Universidade Aberta do Brasil (UAB), tendo iniciado a oferta de seus cursos em 2006. A partir de 2008, participou de todos os editais lançados pela CAPES (Coordenação de Aperfeiçoamento de Pessoal de Nível Superior) e ampliou sua oferta, priorizando os cursos de licenciatura e o atendimento aos polos de apoio presencial que se encontram mais distantes das instituições que ofertam ensino superior público presencial. Isso favorece a inclusão educacional e a qualificação docente para o atendimento da educação básica em parcela significativa do território cearense.

Atualmente, possui 5.676 alunos matriculados, distribuídos em 22 cursos de graduação e pósgraduação lato sensu, com atuação em 34 polos de ensino, do litoral ao extremo sul do estado, abrangendo todo o Ceará. O universo da atual equipe abrange 17 coordenadores, 91 professores formadores, 80 tutores a distância e 73 tutores presenciais.

Para obtenção dos dados, foi realizada a pesquisa no período de junho e julho de 2020. Todos os princípios éticos foram mantidos, e os participantes da pesquisa assinaram Termo de Consentimento Livre e Esclarecido, conforme preconizado pela Resolução 510/2016 do Conselho Nacional de Saúde, que disciplina pesquisas envolvendo seres humanos nas áreas de Ciências Humanas e Sociais (BRASIL, 2016).

Os dados foram coletados a partir da aplicação de questionário on-line, produzido pelo Google Formulários, com perguntas referentes a dados sociodemográficos (4 questões subjetivas e 7 objetivas), à análise dos aspectos ergonômicos em tempos de COVID-19 (1 questão subjetiva e 16 objetivas) e aos impactos do distanciamento social (1 questão subjetiva e 8 objetivas), totalizando 37 questões. Os principais aspectos analisados na ergonomia foram referentes à experiência em suas funções nesse novo momento, horário de serviço, ritmo, turno, desconforto físico/emocional, bem como considerações sobre o atual ambiente de trabalho (home office). As perguntas foram elaboradas com base em Abrahão e Pinho (2002) e Sarmet e Abrahão (2007). No tocante ao distanciamento social, as perguntas buscaram um posicionamento com relação ao protocolo e aos impactos em hábitos pessoais e laborais, com foco em sua produtividade. 
Aspectos ergonômicos e distanciamento social enfrentados por docentes de graduações a distância durante a pandemia

Fátima Aurilane de Aguiar Lima Araripe, Renata Vieira do Nascimento, Lydia Dayanne Maia Pantoja, Germana Costa Paixão

Os dados foram organizados em tabelas com uso de frequências simples e relativas, para facilitar a visualização, e discutidos à luz da literatura, com enfoque na ergonomia e nos aspectos do distanciamento social atual.

\section{RESULTADOS E DISCUSSÃO}

Os resultados estão organizados em três partes: perfil sociodemográfico dos participantes da pesquisa, aspectos ergonômicos em tempos de COVID-19 e os impactos do distanciamento social enfrentados pelos docentes universitários de cursos de graduação a distância.

\section{Perfil sociodemográfico}

Participaram da pesquisa 146 pessoas (N), o que corresponde a $56 \%$ do atual universo da equipe. $O$ perfil mostra a maioria de mulheres no corpo docente. Também se observa um perfil etário mais maduro (média 41,55 anos), 63\% casados, 48,6\% residem com esposa/marido e filhos, 65,1\% afirmam ter filhos, com média de três membros por residência, sendo que 61,6\% moram em casa, conforme a Tabela 1.

\begin{tabular}{|c|c|c|}
\hline Variável & $\mathbf{N}$ & $\%$ \\
\hline \multicolumn{3}{|c|}{ Sexo } \\
\hline Masculino & 64 & 43,8 \\
\hline Feminino & 82 & 56,2 \\
\hline \multicolumn{3}{|c|}{ Idade } \\
\hline Faixa etária $(\bar{X} \pm \mathrm{DP})$ & \multicolumn{2}{|c|}{$41,55 \pm 10,2$} \\
\hline \multicolumn{3}{|c|}{ Estado civil } \\
\hline Casado & 92 & 63 \\
\hline Solteiro & 35 & 24 \\
\hline Separado/Divorciado & 14 & 9,6 \\
\hline Viúvo & 5 & 3,4 \\
\hline \multicolumn{3}{|c|}{ Com quem reside } \\
\hline Esposa/Marido e filhos & 71 & 48,6 \\
\hline Esposa/Marido & 20 & 13,7 \\
\hline Sozinho & 16 & 10,9 \\
\hline Filhos & 14 & 9,6 \\
\hline Pais e Irmãos & 12 & 8,2 \\
\hline Namorados & 7 & 4,8 \\
\hline Parentes & 6 & 4,1 \\
\hline \multicolumn{3}{|c|}{ Membros na residência } \\
\hline № de residentes $(\bar{X} \pm \mathrm{DP})$ & & \\
\hline
\end{tabular}


Fátima Aurilane de Aguiar Lima Araripe, Renata Vieira do Nascimento, Lydia Dayanne Maia Pantoja, Germana Costa Paixão

\begin{tabular}{lcc}
\hline \multicolumn{3}{c}{ Tipo de Residência } \\
\hline Casa & 90 & 61,6 \\
Apartamento & 56 & 38,4 \\
\hline \multicolumn{1}{c}{ Filiação } \\
\hline Possui filhos & 95 & 65,1 \\
\hline $\bar{X}=$ média. DP = Desvio-padrão & &
\end{tabular}

Tabela 1 - Caracterização sociodemográfica de docentes de graduações a distância de uma universidade no estado do Ceará

Fonte: elaborada pelas autoras, 2020.

O perfil feminino segue ao observado mundialmente, havendo o predomínio das mulheres no ensino superior (MCDANIEL, 2014). Os dados tornam-se relevantes, considerando que as mulheres, embora tenham assumido diferentes papéis no mercado de trabalho, ainda sofrem com a sobrecarga oriunda de atividades domésticas e cuidado com filhos. Durante o período de confinamento, isso pode ainda repercutir em um aumento maior de suas demandas/atividades.

Oliveira (2020) reforça o estresse enfrentado pelas mulheres durante a pandemia, tendo em vista a sobrecarga gerada pelo "maternar", já carregado de culpa, e que se agrava com as tarefas domésticas e o trabalho remoto. Essa situação reflete-se da visão cultural de divisão sexual do trabalho, na qual as obrigações domésticas ainda são tidas pela sociedade como de responsabilidade da mulher, impondo a elas renúncias a outras esferas da vida (INSFRAN; MUNIZ, 2020).

A Tabela 2 apresenta o perfil acadêmico dos participantes da pesquisa e o tempo de vínculo a uma graduação a distância. Dentre os profissionais que fazem parte dessa modalidade, constataram-se $40 \%$ biólogos, $19 \%$ pedagogos, 9,5\% engenheiros, $6 \%$ físicos, entre outros. Desses, 37,7\% tinham título de especialista, 28,8\% de mestre, 20,5\% de doutor, 9,6\% de pós doutor e 3,6\% tinham graduação. Atualmente, 34,2\% são professores formadores, $30,8 \%$ são tutores presenciais, $15,8 \%$ são tutores a distância, 17,8\% são coordenadores e 1,4\% atuam de outras formas. $O$ tempo médio de atuação em uma graduação na modalidade a distância foi de 5,74 anos.

\begin{tabular}{lccc}
\hline & Variável & N & \% \\
\hline & Formação acadêmica & & \\
\hline Ciências Biológicas & & 59 & 40 \\
Pedagogia & 28 & 19 \\
Química & 14 & 9,5 \\
Engenharia & 9 & 6 \\
Física & 8 & 5 \\
Matemática & 5 & 4 \\
Educação Física & 4 & 3
\end{tabular}




\begin{tabular}{lcc} 
Enfermagem & 4 & 3 \\
História & 4 & 3 \\
Computação & 3 & 2 \\
Geografia & 3 & 2 \\
Administração & 2 & 1,5 \\
Artes Visuais & 2 & 1,5 \\
Música & Titulação & 0,5 \\
\hline & & 3,4 \\
\hline Graduado & 5 & 37,7 \\
Especialista & 55 & 28,8 \\
Mestre & 42 & 20,5 \\
Doutor & 30 & 9,6 \\
Pós Doutor & 14 & 30,8 \\
\hline Tutor presencial & Atuação & 15,8 \\
Tutor a distância & & 34,2 \\
Professor Formador & 45 & 17,8 \\
Coordenação & 23 & 1,4 \\
Outros & & 50 \\
\hline Tempo (em anos) vinculado a uma graduação a distância & 26 & 2 \\
\hline
\end{tabular}

Tabela 2 - Perfil acadêmico dos participantes e tempo de vínculo a uma graduação a distância de uma universidade de referência no estado do Ceará

Fonte: elaborada pelas autoras, 2020.

A atuação que se destacou foi a de tutor, que, ao somar os tutores presenciais e a distância, totalizaram-se $46,6 \%$ dos participantes. O tutor em cursos a distância exerce um papel de grande importância, uma vez que é um facilitador do processo de ensino-aprendizagem, precisando sempre estar antenado com tudo o que está sendo ministrado, o conteúdo abordado, as metodologias aplicadas e principalmente conhecer a realidade do seu aluno. Os tutores a distância e presencial devem trabalhar em equipe, sendo esta atuação fundamental no desenvolvimento e permanência do aluno no curso de graduação na modalidade remota (BARBOZA; CASTRO, 2017).

\section{Ergonomia em tempos de COVID-19}

Dos 146 respondentes, 54,1\% afirmam que possuem ritmo de trabalho acelerado, 39,7\%, ritmo normal e 6,2\%, ritmo lento. Uma parte dos participantes (32,9\%) trabalha, em média, 20 horas por semana, existindo alguns que disponibilizam 100 horas semanais. Além disso, os partícipes da pesquisa afirmam trabalhar nas atividades da EaD preferencialmente durante a semana $(90,4 \%)$, havendo preferência pelo turno da noite, com 70,5\%. Ainda, 69,2\% preferem a tarde e $51,4 \%$ optam pela manhã. No instrumento de coleta o respondente poderia optar por mais de uma opção, muitos trabalham mais de um turno para realização de suas atividades, por isso ocorre a sobreposição das percentagens. 
A pandemia de COVID-19 modificou de forma acentuada o contexto de alguns profissionais, especialmente os professores formadores que precisaram se adaptar ao estilo de aula remota (BARBOSA; VIEGAS; BATISTA, 2020). No presente estudo, alguns profissionais relataram trabalhar até 100 horas por semana. Evidenciamos que a considerável carga horária pode ser relativa também às novas adaptações ou readaptações, como a suspensão dos encontros presenciais e estágios supervisionados.

Com exceção das aulas remotas, que possuem horários agendados, nota-se que as demais atividades dos participantes têm horário mais flexível, possibilitando a adequação de tempo de acordo com a disponibilidade. A preferência de trabalhar durante a semana e no período noturno corrobora com o trabalho de Paula et al. (2018), que, apesar de ser relativo ao estudo ergonômico da função de tutores, apresenta $86,4 \%$ dos participantes concentrando as atividades no período noturno, de modo que $50,1 \%$ delas ocorrem no decorrer da semana.

Durante a quarentena, devido à pandemia da COVID-19, os participantes da pesquisa passaram a desenvolver suas atividades home office, e, neste sentido, é necessário considerar as condições do local de trabalho na avaliação ergonômica, já que os dados podem influenciar na qualidade da atividade e na saúde do profissional (TABELA 3).

\begin{tabular}{|c|c|c|c|}
\hline Ambiente de trabalho (home office): & Bom (\%) & Regular (\%) & Ruim (\%) \\
\hline Iluminação & 83,6 & 15,8 & 0,7 \\
\hline Ruído & 52,1 & 42,5 & 5,5 \\
\hline Conforto térmico & 64,4 & 30,8 & 4,8 \\
\hline Vibrações no ambiente & 63 & 31,5 & 5,5 \\
\hline Condições do espaço & 71,9 & 26 & 2,1 \\
\hline $\begin{array}{l}\text { Qualidade de ferramentas e equipamento de } \\
\text { trabalho }\end{array}$ & 78,8 & 19,9 & 1,4 \\
\hline Relacionamento com demais tutores & 95,9 & 4,1 & - \\
\hline $\begin{array}{l}\text { Relacionamento com a coordenação geral do curso } \\
\text { (coordenação de polo, Secretaria de Apoio às }\end{array}$ & 95,2 & 4,8 & - \\
\hline Tecnologias Educacionais...) & & & \\
\hline $\begin{array}{l}\text { Distribuição das tarefas por parte da coordenação } \\
\text { do curso }\end{array}$ & 91,8 & 7,5 & 0,7 \\
\hline Atendimento as suas sugestões e solicitações & 87,7 & 12,3 & - \\
\hline
\end{tabular}

Tabela 3 - Situação do home office de membros de diferentes cursos de graduação, modalidade a distância

Fonte: elaborada pelas autoras, 2020. 
Observou-se que a maioria das respostas quanto à qualidade do local de trabalho foi positiva. Possivelmente isso está relacionado ao fato de os indivíduos já terem o hábito de trabalhar remotamente, uma vez que já faziam parte da educação a distância e tinham um ambiente de trabalho mais confortável (TABELA 3).

Na Tabela 3, também é possível observar a boa relação entre os profissionais. Isso é um fator importante para um bom ambiente de trabalho, uma vez que, quando motivados, os profissionais tendem a contribuir mais com o grupo (BRANDÃO; FREITAS, 2019). Este é um fator preponderante especialmente dentro de um contexto pandêmico, no qual todas as reuniões de grupo estão acontecendo on-line e os profissionais precisam se reinventar. Além disso, os docentes julgaram seus cursos como tendo boa distribuição de tarefas e atendendo bem as sugestões/solicitações, também sendo estes fatores que fazem a diferença na motivação e no bom andamento do ensino.

Os partícipes foram questionados se o curso de graduação a distância em que atuam oferece condições necessárias para obter os resultados que são cobrados em tempos de pandemia. Dentre os participantes, $88,4 \%$ responderam que sim, enquanto $11,6 \%$ alegaram que os prazos oferecidos pelo curso eram apertados ou que novas demandas estavam chegando muito rápido, gerando sobrecarga.

Gusso et al. (2020) apontam que a atividade remota emergencial exigida em tempos de pandemia não somente levou à utilização não planejada de recursos on-line, mas também desconsiderou aspectos importantes das realidades de estudantes e professores, no que concerne aos aspectos pedagógicos e tecnológicos envolvidos. Estes autores também acrescentam que a sobrecarga do trabalho docente está relacionada às múltiplas atividades atribuídas ao planejamento, readequação, capacitação, desafios para lidar com as tecnologias, além do tempo reduzido para desempenhar cada uma delas.

Sobre sentirem algum desconforto físico durante a realização do trabalho, 62,3\% responderam que não. Dos que responderam $\operatorname{sim}(37,7 \%)$, os motivos relatados estão relacionados ao tempo que estão passando sentados em frente ao computador, o que tem gerado dores nas costas, ou em outras partes do corpo, bem como possíveis problemas de visão e, até mesmo, dores de cabeça. Quando indagados se apresentam algum tipo de desconforto emocional, $65,1 \%$ responderam que não, e $34,9 \%$ relataram preocupação com os familiares, ansiedade e saudades de desenvolver atividades presenciais com alunos.

Ansiedade, estresse e diminuição da qualidade do sono são sintomas que atingiram as pessoas especialmente durante o período de distanciamento social (XIAO et al., 2020). De forma geral, esse período de distanciamento faz com que as pessoas fiquem mais propensas a preocupações com a saúde de amigos e familiares e se afetem bastante pela falta de interação 
social. Já com relação aos participantes, esses profissionais mantiveram contato virtual com alunos. Contudo, os encontros presenciais anteriores à pandemia foram substituídos por encontros virtuais que demandaram sobrecarga na preparação de materiais didáticos e desafios relacionados a um novo formato de aulas, o que pode ter contribuído com fatores estressantes.

\section{Impactos do distanciamento social}

No tocante ao posicionamento dos participantes da pesquisa sobre a gravidade da pandemia da COVID-19 no Brasil, 81,5\% consideraram muito grave e 18,5\%, grave, enquanto no estado do Ceará, $66,4 \%$ acreditaram ser muito grave e $33,6 \%$, grave. Além de considerarem a situação como de alta gravidade, $99,3 \%$ dos participantes afirmaram que o distanciamento social é necessário, e $83,6 \%$ relataram que estão praticando-o totalmente, enquanto $16,4 \%$, parcialmente.

Desde março de 2020, diversos estados brasileiros iniciaram o período de quarentena e distanciamento social, momento no qual também foi proibido por lei aglomerações sociais e se tornou obrigatório o fechamento temporário de serviços não essenciais. Já que os dados podem influenciar na qualidade, observamos, em nossa pesquisa, que os respondentes têm consciência da gravidade da pandemia da COVID-19, bem como estavam praticando o distanciamento social recomendado. Sousa Júnior et al. (2020) relatam em seus estudos que os cidadãos brasileiros entendem a importância do isolamento social e tentaram praticá-lo, ainda que aleguem que fatores financeiros complicam esta medida restritiva.

Na Tabela 4, observam-se os impactos/transformações que o distanciamento social tem gerado nos hábitos pessoais dos participantes. Os respondentes poderiam marcar mais de uma alternativa disponibilizada.

\begin{tabular}{llc}
\hline \multicolumn{1}{c}{ Hábitos pessoais } & Percentual \\
\hline 1. & \multicolumn{1}{c}{ Tenho tido alterações no sono } & 63,7 \\
2. Tenho consumido mais alimentos do que o & 65,8 \\
& habitual & 6,2 \\
3. Tenho consumido menos alimentos do que o & \\
$\quad$ habitual & 11,6 \\
4. Tenho consumido mais bebidas alcoólicas do que &
\end{tabular}


5. Tenho consumido menos bebidas alcoólicas do que o habitual

6. Tenho assumido mais obrigações 78,1 domésticas/familiares do que o habitual

7. Tenho assumido menos obrigações 1,4 domésticas/familiares do que o habitual

8. Tenho feito mais uso das mídias tradicionais e 94,5 digitais para desenvolver atividades de trabalho/estudo

9. Tenho feito mais uso das mídias tradicionais e 40,4 digitais para diversão e lazer

10. Tenho feito mais uso das mídias tradicionais $\mathrm{e}$ digitais para buscar informações do contexto atual

11. Outro

Tabela 4 - Impactos/transformações ocasionados na vida dos profissionais de cursos a distância Fonte: elaborada pelas autoras, 2020.

Mais da metade dos respondentes afirmam que a situação de pandemia e, consequentemente, as condições de distanciamento social geraram alterações de sono $(63,7 \%)$, consumo de alimentos maior que o habitual $(65,8 \%)$, mais obrigações domésticas/familiares $(78,1 \%)$ e aumento do uso das mídias tradicionais e digitais para desenvolver atividades de trabalho/estudo (94,5\%) e para buscar informações relacionadas ao contexto atual $(71,2 \%)$.

Esse cenário também foi descrito por Xiao et al. (2020), ao observar sintomas que afetaram negativamente o psicológico das pessoas durante a pandemia, como compulsões e transtornos do sono. Além dos problemas psicológicos, é possível observar que os respondentes também foram submetidos a outras situações de estresse, uma vez que relataram que assumiram atividades domésticas. Isso é compreensível, pois supõe-se que talvez estes, se tivessem alguma ajuda externa (empregados domésticos), precisaram dispensá-la devido a pandemia e assumiram tais obrigações. Outra situação de estresse observada foi o aumento da demanda de mídias tradicionais e digitais com fins de estudo/trabalho. Isso provavelmente se relaciona à necessidade de inovar nas aulas e com seus alunos durante esse período conturbado e de um tempo maior na preparação de aulas e no contato com os estudantes. 
Os que marcaram a opção "outro" relataram sentir falta de poder realizar atividades ao ar livre, como por exemplo exercícios físicos, e, por isso, tem-se utilizado da internet para tentar desenvolver atividades físicas, meditação etc. Além disso, foi relatada também maior responsabilidade dentro de casa, pois alguns moram com pessoas do grupo de risco para COVID-19, colocando-se na obrigação de ir ao supermercado, por exemplo.

A prática de exercícios físicos é fortemente relacionada ao aumento da imunidade. Inclusive, a Sociedade Brasileira de Medicina do Exercício e do Esporte (SBMEE, 2020) lançou informes sobre a importância da prática de exercício físicos para a saúde dentro de um contexto pandêmico. O período de reclusão domiciliar torna a população mais sedentária, o que pode acarretar problemas físicos e psicológicos, como sobrepeso e ansiedade, respectivamente.

Sobre as atividades no trabalho, $48,6 \%$ dos respondentes mantiveram a produtividade, $33,6 \%$ aumentaram-na, 19,2\% diminuíram-na, e a 0,7\% o questionamento não se aplica. Na Tabela 5 , podem-se observar as possíveis razões que levaram o profissional a aumentar a produtividade no trabalho. O respondente podia marcar mais de uma alternativa disponibilizada.

\begin{tabular}{llc}
\hline \multicolumn{2}{c}{ Motivos para aumento da produtividade } & Percentual \\
\hline 1. Aumento do tempo disponível & 49,3 \\
2. Aumento da demanda ou da inspiração & 68,7 \\
impulsionadas pelo contexto atual & \\
3. Boa adaptação a execução de atividades remotas & 38,8 \\
4. Maior concentração para realização de atividades & 23,9 \\
\hline
\end{tabular}

Tabela 5 - Possíveis motivos que podem ter causado aumento da produção de trabalho Fonte: elaborada pelas autoras, 2020.

O aumento do tempo livre $(49,3 \%)$ e o aumento da demanda/inspiração $(68,7 \%)$ foram os principais fatores destacados por manter ou aumentar a produtividade dos participantes da pesquisa. Para os professores, também pode-se justificar esse resultado pelo fato de que muitas atividades precisaram ser readequadas para que o semestre pudesse ser finalizado com êxito. Assim, foi necessário adaptar os momentos presenciais para aulas remotas, além do desempenho de outras atividades que motivassem os alunos a permanecerem no curso, especialmente durante a pandemia, como palestras e cursos, já que o contexto gerou incertezas para todos.

Pontes e Rostas (2020) destacam, nesse sentido, a intensificação da precarização do trabalho gerado pelo aumento das demandas, estabelecida principalmente pela necessidade de 
aprender a usar novas ferramentas, adequação das práticas presenciais de ensino em uma realidade de intensas pressões emocionais geradas pela própria condição da doença (COVID19), mudança de rotina e sobreposição de papéis, seja na atividade laboral ou em casa.

Na Tabela 6, observa-se os possíveis motivos pelos quais houve diminuição da produtividade no trabalho, estando, entre os principais, as dificuldades de conciliar a demanda doméstica com o trabalho/estudo (60\%), a dificuldade de acesso a computadores (14,3\%) e a falta de capacitação para desenvolver o trabalho remotamente $(14,3 \%)$. Os que marcaram a opção "outro" relataram que a própria casa não é muito adequada para estudo/pesquisa ou que contraíram COVID-19. O respondente podia marcar mais de uma alternativa disponibilizada.

\begin{tabular}{|c|c|}
\hline Motivos para diminuição da produtividade & Percentual \\
\hline 1. Dificuldade de acesso a computadores & 14,3 \\
\hline 2. Dificuldade de acesso à internet & 5,7 \\
\hline $\begin{array}{l}\text { 3. Dificuldade de conciliar a demanda doméstica } \\
\text { com a demanda de trabalho/estudo }\end{array}$ & 60 \\
\hline $\begin{array}{l}\text { 4. Falta de capacitação para desenvolver o trabalho } \\
\text { de forma remota }\end{array}$ & 14,3 \\
\hline $\begin{array}{l}\text { 5. Interferência de condições } \\
\text { psicológicas/emocionais no desenvolvimento das } \\
\text { atividades de trabalho/estudo }\end{array}$ & 74,3 \\
\hline 6. Outro & 1,4 \\
\hline
\end{tabular}

Tabela 6 - Possíveis motivos que podem ter causado queda da produção de trabalho Fonte: elaborada pelas autoras, 2020.

Cerca de $20 \%$ dos participantes relataram diminuição da produtividade durante o distanciamento social, e o motivo que se destaca para isso é a questão emocional, já que $74,3 \%$ dos participantes relataram interferência de condições psicológicas/emocionais no desenvolvimento das atividades de trabalho/estudo. Segundo Pontes e Rostas (2020, p. 279), isso se deve ao surgimento de novos padrões de trabalho que provocaram "instabilidade emocional e psicológica com efeitos psicossomáticos no organismo, atingindo diretamente o professor, que apesar do trabalho essencialmente intelectual sobrecarrega-se ao limite".

Sahu (2020) relata ainda um alto estresse nos alunos e funcionários de universidades, podendo esse acarretar problemas de aprendizagem. Assim, segundo esse mesmo autor, é necessário que o professor passe por acompanhamento psicológico, para cuidar de si, e de 
treinamentos tecnológicos, a fim de se aperfeiçoar com novas tecnologias e tentar trazer aulas mais interativas.

\section{CONSIDERAÇÕES FINAIS}

Considerando a complexidade dos elementos que podem contribuir para as repercussões ergonômicas junto aos participantes da pesquisa (profissionais do ensino superior) em home office, os dados obtidos tornam-se relevantes para assessorar os gestores no que se refere à dinâmica das atividades, que acontecem ao longo de graduações a distância, e em permitir uma reflexão da própria prática educacional em tempos tão adversos.

No tocante aos impactos do distanciamento social, destaca-se o aparecimento de problemas psicológicos, como distúrbios do sono, e situações de estresse, como a dificuldade de conciliar a demanda doméstica com a demanda de trabalho/estudo, posto que a maioria dos respondentes são mulheres que também se desdobram em várias funções domésticas. Isso permite reflexões para futuros estudos que visualizem o impacto do distanciamento social frente à vida desses profissionais e o que pode ser feito para mitigar e ensinar a conciliar ambas as situações.

Também se constatou que a pandemia da COVID-19 trouxe novos desafios aos profissionais que trabalham em cursos de graduação a distância, que se refletiram, inclusive, em sua saúde mental. Nesse sentido, observa-se que a pandemia intensificou problemas já vivenciados por muitos profissionais de universidades, quando se trata da sobrecarga e das condições de trabalho, além da falta de assistência à saúde desses funcionários por parte das instituições de ensino. É necessário que a demanda de trabalho respeite as condições pessoais de cada profissional, considerando a disponibilidade de espaço, os recursos tecnológicos, as demandas domésticas e os cuidados com os filhos, estes últimos impostos, principalmente, às mulheres.

Além disso, é necessário que as instituições forneçam cursos para minimizar as dificuldades com as tecnologias, exigidas pelo trabalho home office, além de oferecer serviço de apoio à saúde mental para os profissionais que necessitarem. Sobretudo, é relevante acolher esses profissionais, compreender que, para além das suas capacidades profissionais, há um indivíduo que precisa de cuidados com relação à sua saúde física e mental perante as vulnerabilidades psicológicas, sociais, econômicas e laborais que os atingem.

Por fim, afirma-se que mais estudos devem ser estimulados para que se entenda a dinâmica de adaptação frente aos aspectos ergonômicos e os impactos do distanciamento social enfrentados por profissionais inseridos em cursos de graduação a distância, atentando para o atual contexto pandêmico. 


\section{REFERÊNCIAS}

ABRAHÃO, Julia Issy; PINHO, Diana Lúcia Moura. As transformações do trabalho e desafios teórico-metodológicos da Ergonomia. Estudos de Psicologia, Natal, v. 7, n. especial, p. 45-52, 2002. DOI: https://doi.org/10.1590/S1413-294X2002000300006.

BARBOSA, Andre Machado; VIEGAS, Marco Antônio Serra; BATISTA, Regina Lucia Napolitano Felício Felix. AULAS PRESENCIAIS EM TEMPOS DE PANDEMIA: relatos de experiências de professores do nível superior sobre as aulas remotas. Revista Augustus, Rio de Janeiro, v. 25, n. 51, p. 255-280, 2020. DOI: https://doi.org/10.15202/1981896.2020v25n51p255.

BARBOZA, Valeria Gomes; CASTRO, Márcia Prado. Competências e Habilidades Necessárias ao Tutor na Educação à Distância. Revista Acadêmica Integra/Ação, [S.I.], v. 1, n. 1, p. 237250, 2017. DOI: https://doi.org/10.22287/integraacao.v1i1.523.

BRANDÃO, Ana Cristina da Silva; FREITAS, Michelle. A IMPORTÂNCIA DA MOTIVAÇÃO E SUA INFLUÊNCIA NO AMBIENTE DE TRABALHO: Um estudo de caso no Instituto Federal de Educação, Ciência e Tecnologia de Mato Grosso-Campus Juína. Revista Científica da Ajes, Juína, v. 8, n. 17, 2019.

BRASIL. Normas Regulamentadoras de Segurança e Medicina do Trabalho. NR 17 Ergonomia. Ministério do Trabalho e Emprego, Brasília, DF. 2007. Disponível em:

http://www.pncq.org.br/uploads/2012/09/NR-17.pdf. Acesso em: 08 jul. 2018.

BRASIL, Ministério da Saúde. Resolução № 510, de 07 de abril de 2016. Diretrizes e Normas de Pesquisa em Seres Humanos para pesquisas em Ciências Humanas e Sociais. Conselho Nacional de Saúde, Brasília, DF. 2016.

GIL, Antônio Carlos. Métodos e Técnicas de Pesquisa Social. 6. ed. São Paulo: Atlas, 2008.

GUSSO, Helder Lima; ARCHER, Aline Battisti; LUIZ, Fernanda Bordignon; SAHÃO, Fernanda Torres; LUCA, Gabriel Gomes; HENKLAIN, Marcelo; PANOSSO, Mariana Gomide; KIENEN, Nádia; BELTRAMELLO, Otávio; GONÇALVES, Valquiria Maria. Ensino Superior em Tempos de Pandemia: Diretrizes à Gestão Universitária. Educação e Sociedade, Campinas, v. 41, p. 26, 2020. DOI: https://doi.org/10.1590/es.238957.

INSFRAN, Fernanda Fochi Nogueira; MUNIZ, Ana Guimarães Correa Ramos. Maternagem e Covid-19: desigualdade de gênero sendo reafirmada na pandemia. Diversitates International Journal, Niterói, v. 12, n. 2, p. 26-47, 2020.

MCDANIEL, Anne. Women's Rising Share of Tertiary Enrollment: A Cross-National Analysis. FIRE: Forum for International Research in Education, Texas, v. 1, n. 2, p. 1-21, 2014. DOI: https://doi.org/10.18275/fire201401021016.

ODRIOZOLA-GONZÁLEZ, Paula; PLANCHUELO-GÓMEZ, Álvaro; IRURTIA, María Jesús; LUISGARCÍA, Rodrigo de. Psychological effects of the COVID-19 outbreak and lockdown among 
students and workers of a Spanish university. Psychiatry Research, [S.I.], v. 290, p. 1-8, 2020. DOI: http://dx.doi.org/10.1016/j.psychres.2020.113108.

OLIVEIRA, Anita Loureiro de. A espacialidade aberta e relacional do lar: a arte de conciliar maternidade, trabalho doméstico e remoto na pandemia da COVID-19. Revista Tamoios, Rio de Janeiro, v. 16, n. 1, p. 154-166, 2020. DOI:

https://doi.org/10.12957/tamoios.2020.50448.

ORNELL, Felipe; SCHUCH, Jaqueline B.; SORDI, Anne O.; KESSLER, Felix Henrique Paim. "Pandemic fear" and COVID-19: mental health burden and strategies. Brazilian Journal of Psychiatry, [S.I.], v. 42, n. 3, p. 232-235, 2020. DOI: http://dx.doi.org/10.1590/1516-44462020-0008.

PAULA, Francisco Wagner de Sousa; CASTRO, Laura Helena Pinto de; PANTOJA, Lydia Dayanne Maia; PAIXÃO, Germana Costa. Análise ergonômica da função de tutoria em um curso de graduação a distância. In: XV CONGRESSO BRASILEIRO DE ENSINO SUPERIOR A DISTÂNCIA E IV CONGRESSO INTERNACIONAL DE EDUCAÇÃO SUPERIR A DISTÂNCIA - ESUD, 2018. Natal. Anais [...] Natal: ESUD, 2018.

PONTES, Fernanda Rodrigues; ROSTAS, Márcia Helena Sauaia Guimarães. Precarização do trabalho do docente e adoecimento: COVID-19 e as transformações no mundo do trabalho, um recorte investigativo. Revista Thema, Pelotas, v. 18, n. 1, p. 278-300, 2020. DOI: https://doi.org/10.15536/thema.V18.Especial.2020.278-300.1923.

RICHTER, Alexander. Locked-down digital work. International Journal Of Information Management, [S.I.], v. 55, p. 1-3, 2020. DOI: http://dx.doi.org/10.1016/j.ijinfomgt.2020.102157.

SAHU, Pradeep. Closure of Universities Due to Coronavirus Disease 2019 (COVID-19): Impact on Education and Mental Health of Students and Academic Staff. Cureus, Palo Alto, v. 12, n. 4, p. 1-6, 2020. DOI: http://doi.org/10.7759/cureus.7541.

SARMET, Mauricio Miranda; ABRAHÃO, Julia Issy. O tutor em Educação a Distância: análise ergonômica das interfaces mediadoras. Educação em Revista, Belo Horizonte, n. 46. p. 109141, 2007. DOI: https://doi.org/10.1590/S0102-46982007000200004.

SHIGEMURA, Jun; URSANO, Robert J.; MORGANSTEIN, Joshua C.; KUROSAWA, Mie; BENEDEK, David M. Public responses to the novel 2019 coronavirus (2019-nCoV) in Japan: mental health consequences and target populations. Psychiatry and Clinical Neurosciences, [S.I.], v. 74, n. 4, p. 281-282, 2020. DOI: http://dx.doi.org/10.1111/pcn.12988.

SBMEE. Informe da Sociedade Brasileira de Medicina do Exercício e do Esporte (SBMEE) sobre exercício físico e o coronavírus (COVID-19). São Paulo: SBMEE, 2020. Disponível em: http://www.medicinadoesporte.org.br/wpcontent/uploads/2020/03/sbmee_covid19_final.pdf. Acesso em: 04 ago. 2020. 
Aspectos ergonômicos e distanciamento social enfrentados por docentes de graduações a distância durante a pandemia

Fátima Aurilane de Aguiar Lima Araripe, Renata Vieira do Nascimento, Lydia Dayanne Maia Pantoja, Germana Costa Paixão

SOUSA JÚNIOR, João Henriques de; IWAYA, Gabriel Horn; CARDOSO, Janaína Gularte;

FARIAS, Miriam Leite; SILVA, Bianca Gabriely Ferreira. O distanciamento social na percepção dos brasileiros. Revista Encantar-Educação, Cultura e Sociedade, Bom Jesus da Lapa, v. 2, p. 1-10, 2020. DOI: http://dx.doi.org/10.46375/encantar.v2.0024.

XIAO, Han; ZHANG, Yan; KONG, Desheng; LI, Shiyue; YANG, Ningxi. Social capital and sleep quality in individuals who self-isolated for 14 days during the coronavirus disease 2019 (COVID-19) outbreak in January 2020 in China. Medical science monitor: international medical journal of experimental and clinical research, [S.I.], v. 26, p. e923921-1-e923921-8, 2020. DOI: http://doi.org/10.12659/MSM.923921. 
Fátima Aurilane de Aguiar Lima Araripe, Renata Vieira do Nascimento,

Lydia Dayanne Maia Pantoja, Germana Costa Paixão

\section{Fátima Aurilane de Aguiar Lima Araripe}

Doutora em Desenvolvimento e Meio Ambiente pela Universidade Federal do Rio Grande do Norte (2020), Mestra em Desenvolvimento e Meio Ambiente pela Universidade Federal do Ceará (2016), especialista em Gestão Ambiental e Desenvolvimento sustentável pela Faculdade Stella Maris (2015) e graduada em Ciências Biológicas pela Universidade Estadual do Ceará (2013). É tutora a distância do Curso de Ciências Biológicas da Universidade Estadual do Ceará (UAB/UECE), com experiência em docência presencial e a distância na educação básica e superior, nas áreas de Meio Ambiente, Educação Ambiental, Sustentabilidade e Ecologia Aplicada, com ênfase em Biologia da Conservação, atuando principalmente na Conservação no Bioma Caatinga.

fatima.aurilane@uece.br

\section{Renata Vieira do Nascimento}

Graduada em Ciências Biológicas pela Universidade Estadual do Ceará (UECE) e mestra em Ciências Veterinárias (UECE). Atualmente, é estudante de doutorado do programa de pósgraduação em Ciências Veterinárias (UECE) e tutora a distância do curso de Ciências Biológicas da UAB/UECE. Tem experiência na área de Biotecnologia da Reprodução, com ênfase em Reprodução de Peixe (caracterização seminal, criopreservação seminal e fertilização).

renata.nascimento@uece.br

\section{Lydia Dayanne Maia Pantoja}

Doutora em Engenharia Civil (Saneamento Ambiental) pela Universidade Federal do Ceará (UFC); mestre em Microbiologia Médica pela UFC e graduada em Ciências Biológicas pela Universidade Estadual do Ceará (Bacharel e Licenciatura) (UECE). Atua como professora assistente nível D da Universidade Estadual do Ceará. Docente do Mestrado Profissional em Ensino de Biologia em Rede Nacional (PROFBIO). Coordena a pesquisa do curso de Ciências Biológicas a distância (UECE/UAB). É coordenadora de área do Curso Pré-Universitário UECEVest - Biologia. Tem experiência na área de Microbiologia, com ênfase em Microbiologia Ambiental e Aplicada, bem como desenvolve trabalhos na área de pesquisa em Educação a Distância e Formação de Professores.

lydia.pantoja@uece.br

\section{Germana Costa Paixão}

Graduada em Medicina Veterinária pela Universidade Estadual do Ceará, mestre em Patologia pela Universidade Federal do Ceará (UFC) e doutoranda em Microbiologia Médica também pela UFC, desde 2018. Professora da Universidade Estadual do Ceará (UECE) desde 2000 e coordenadora do curso de Ciências Biológicas a distância da Universidade Aberta do Brasil (UAB/UECE), desde 2009. Docente do curso de Enfermagem do Centro Universitário Unifametro. Leciona as disciplinas de Microbiologia, Parasitologia e Exames Laboratoriais. É líder do grupo de pesquisas certificado pelo CNPq, intitulado "Tecnologias educacionais e educação a distância", desenvolve pesquisas nas áreas de taxonomia de dermatófitos, fungos anemófilos e produção de material em Microbiologia.

germana.paixao@uece.br 